\title{
A Logic Circuit Simulation for Choosing a Group or a Question using Register and Encoder
}

\author{
Lianly Rompis \\ Electrical Engineering Study Program, Faculty of Engineering, \\ Universitas Katolik De La Salle Manado; \\ Irompis@unikadelasalle.ac.id
}

\begin{abstract}
Besides learning and working individually, normally people also interact in a group. A teacher or manager will divide and put several persons in groups, and mostly the group arrangement will be organized according to some classifications. This is quite different when people are dealing with a specific game or quiz. The participants will be asked to choose their own group or question in random order. Using the basic concept of digital system and electronic workbench 5.12 software, a logic circuit could be designed to build a circuit simulation consists of register and encoder which can be used to choose a group or a question randomly. The methods being used are study literature, analysis, design, and simulation. The result shows a desired output, a logic circuit for choosing a group or a question can be built using register and encoder logic components. Once a group or a question has been chosen, it cannot be chosen and displayed again.
\end{abstract}

Keywords: Choosing a Group; Choosing a Question; Logic Circuit Simulation; Register; Decoder.

\section{Introduction}

People sometimes do social interactions in daily works or learning. Generally the most fun interactions are quiz and game. When people are dealing with a specific game or quiz, they will be asked to choose their own group or question in a random order. Developing the basic concept of digital system we have learned and applying electronic workbench 5.12 software, we can try to build a simple and fun logic circuit simulation consists of main components: register and encoder, which can be used to choose a group or a question randomly. Once a group or a question has been chosen, it cannot be chosen and displayed again.

\section{Methods}

Learning from several methodologies from [8], the methodology being used for this research mainly to understand the basic concept and combine the functions of shift register and encoder, to derive a new and simple form of designing a counter.

\section{Basic Theories}

\subsection{Synchronous Counter}

Synchronous Counter is a type of sequential logic circuit functions for counting binary information, which clock input of all the flip-flop components are connected together and triggered by the input pulses. Thus, all the flip-flops would change state simultaneously, in parallel $[1,2,6,7]$. The number of 
Lianly Rompis; A Logic Circuit Simulation for Choosing a Group or a Question using Register and Encoder. Advances in Image and Video Processing, Volume 6 No 1, February (2018); pp: 13-17

bit depends on number of flip-flop being used. For example, in Figure 1, to have a design output values in 3-bit length, the number of flip-flop that we used is 3 (three) also. The bit-sequences are given in Table 1.

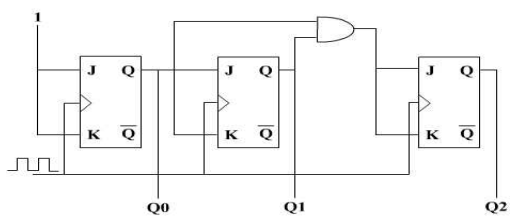

Figure 1. 3-bit synchronous counter

Table 1. The bit sequence of 3-bit synchronous counter

\begin{tabular}{|c|c|c|}
\hline FF2 & FF1 & FF0 \\
\hline \hline 0 & 0 & 0 \\
\hline 0 & 0 & 1 \\
\hline 0 & 1 & 0 \\
\hline 0 & 1 & 1 \\
\hline 1 & 0 & 0 \\
\hline 1 & 0 & 1 \\
\hline 1 & 1 & 0 \\
\hline 1 & 1 & 1 \\
\hline
\end{tabular}

\subsection{Shift Register}

Shift register is another type of sequential logic circuit, mainly for storing digital data. They are a group of flip-flops, usually D-FF, connected in a loop so that the output from one flip-flop becomes the input of the next flip-flop, and so on [1,2,5]. All the flip-flops are driven by a common clock, and all are set or reset simultaneously. This is shown in Figure 2.

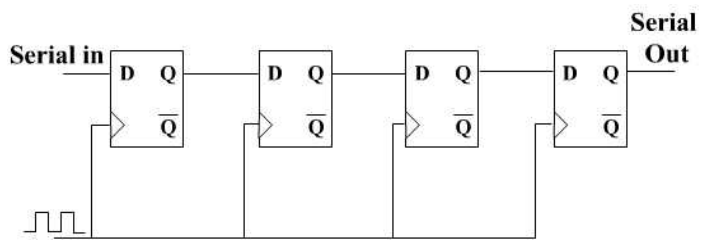

Figure 2. Right shift register

\subsection{Encoder}

Encoder is a type of combinational logic circuit, mostly used in data encoding. The design for encoder comes from logic gate circuits. It has an input of $2^{n}$ lines and output $n$ lines as being referred in $[1,2,3,4]$.

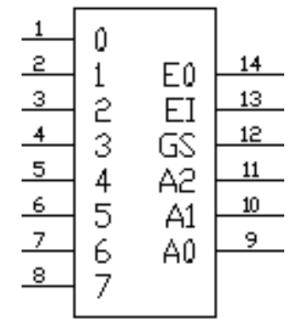

Figure 3. Encoder 8-to-3 
A simple form of low-active encoder is shown in Figure 3. The outputs will activate a binary number combination based on the active input and priority. To understand how a priority encoder works, there is a characteristic table being given in Table 2. If logic 1 is given to more than one input of priority encoder, the output will read the highest input level, and transfer it as a combination of output.

Table 2. Tuth table of a priority encoder

\begin{tabular}{|c|c|c|c|c|c|}
\hline \multicolumn{5}{|c|}{ INPUTS } & \multicolumn{2}{c|}{ OUTPUTS } \\
\hline D0 & D1 & D2 & D3 & A & B \\
\hline \hline 1 & 0 & 0 & 0 & 0 & 0 \\
\hline 0 & 1 & 0 & 0 & 0 & 1 \\
\hline 0 & 0 & 1 & 0 & 1 & 0 \\
\hline 0 & 0 & 0 & 1 & 1 & 1 \\
\hline$x$ & 1 & 0 & 0 & 0 & 1 \\
\hline$x$ & $\mathrm{x}$ & 1 & 0 & 1 & 0 \\
\hline $\mathrm{x}$ & $\mathrm{x}$ & $\mathrm{x}$ & 1 & 1 & 1 \\
\hline
\end{tabular}

\section{Analysis and Design}

\subsection{Analysis}

A right shift register has a very simple form like the circuit diagram in Figure 2. It functions a serial input. The binary input will come from the left side, and shifted to the right. Every clock cycle will shift one bit to the right. We can add as many flip-flops as we need, according to our design, as explained in $[2,3,5]$. What will happen if we try to modify the right shift register circuit by adding an XNOR gate? With this circuit connection, the LED light will light one by one each cycle: $100,010,001,100, \ldots$ etc. The related logic circuit is shown in Figure 4.

Table 3. Tuth table of an xnor gate

\begin{tabular}{|c|c|c|}
\hline \multicolumn{2}{|c|}{ INPUTS } & OUTPUT \\
\hline \hline A & B & Y \\
\hline \hline 0 & 0 & 1 \\
\hline 0 & 1 & 0 \\
\hline 1 & 0 & 0 \\
\hline 1 & 1 & 1 \\
\hline
\end{tabular}

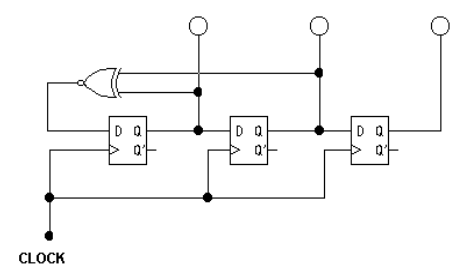

Figure 4. Right shift register with an xnor gate

At an initial condition, the outputs of all Flip-flops are 0 s and will turn into $1 \mathrm{~s}$ if the inputs are $1 \mathrm{~s}$. From the circuit we can see that $Q_{1}=0$ and $Q_{2}=0$, being an input for XNOR Gate. The output of Xnor gate will give logic 1 , so input $D$ will become 1 . The next clock cycle will set the output of $Q_{1}=1$, and followed by $\mathrm{Q}_{2}=1$ again in the next cyle. When $\mathrm{Q}_{1}$ was changing into $1 \mathrm{~s}$, Xnor gate will give an output of $0 \mathrm{~s}$, turn $\mathrm{D}$ 
Lianly Rompis; A Logic Circuit Simulation for Choosing a Group or a Question using Register and Encoder. Advances in Image and Video Processing, Volume 6 No 1, February (2018); pp: 13-17

into 0 s once again. The next cycle will give an output of $Q_{1}=0$, and so on. These happen continuously and build a same loop of function.

\subsection{Design}

In my research, the output of right shift register is connected as an input for encoder to build a synchronous counter $1-3$, as shown in figure 5.

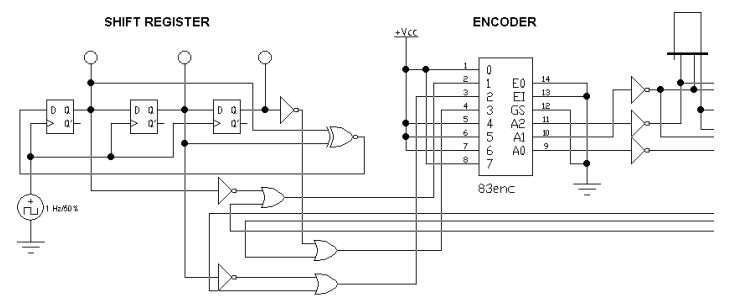

Figure 5. Synchronous counter with shift register and encoder

Each output of D FFs is connected to the correspond number in encoder. The output will display 1 to 3 continuously.

To choose a group or number, we must use a switch. Once a group or a question has been chosen, it cannot be chosen and displayed again, so we will need a component to lock the number being chosen so it will not display again in the counter output. In here an R-S latch has been used for that function, and a $\mathrm{D}$ latch is used to display the picked up group or question.

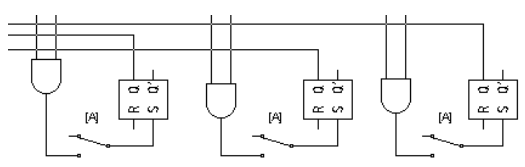

(a)

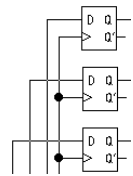

(b)

Figure 6. (a) Switch and (b) D-latch

\section{Simulation}

Now we can try to connect all the logic parts and integrate them together to build the logic circuit for a quiz or a game. From the simulations using software Electronic Workbench 5.12, the circuit works well and gives the right output. The synchronous counter displays a number between 1 to 3 . A participant needs to push the button switch to pick up a group or question from the counter. When the switch already selects the number, the counter will start to count again without the number already chosen or displayed. Now it is the next participant turn to push the button switch and select from the rest of numbers. In this simulation, I used a $1 \mathrm{~Hz}$ clock in order to be able to follow the counter display.

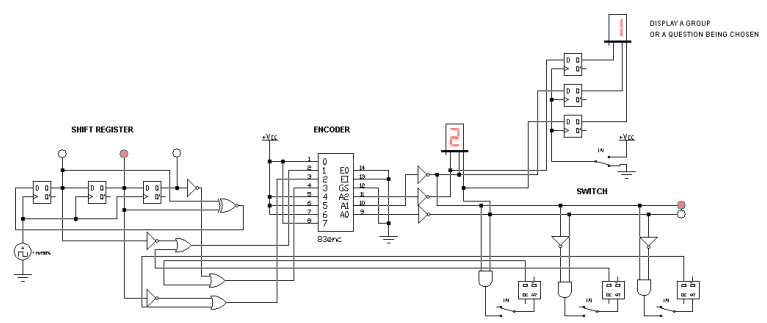

Figure 7. First Simulation shows that group/question 1 is being chosen from loop counter (1 to 3 ) 


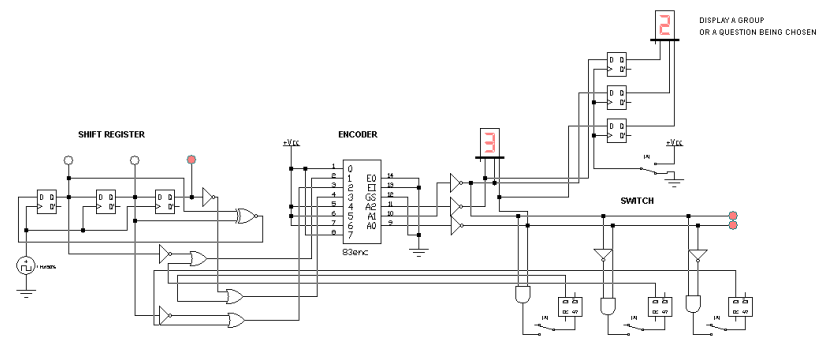

Figure 8. Second Simulation shows that group/question 2 is being chosen from loop counter ( 2 and 3 )

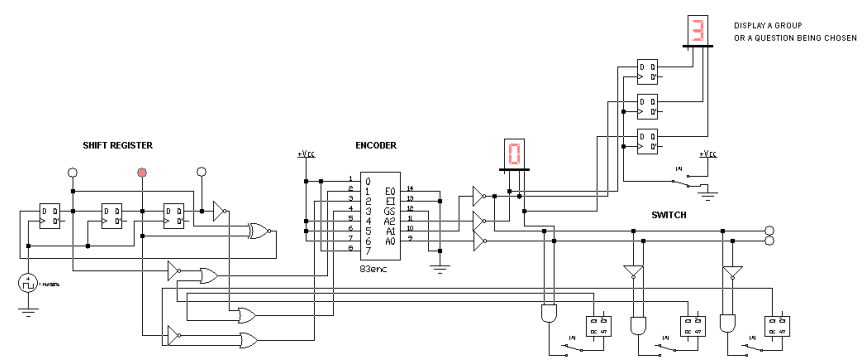

Figure 9. Third Simulation shows that the only option left is being chosen: group/question 3

\section{Conclusion}

Using Register and Encoder, we can build a logic circuit simulation for choosing a group or a question. Uniquely, once a group or a question being selected by a participant, it cannot be selected or displayed anymore by other participants. That is why it will be fun to use this simulation for a game or a quiz. The logic circuit simulation only used a low frequency clock so we could see the changes shown by the counter. It must be upgraded into a high frequency clock so participants cannot see the numbers and randomly can select one of them. For this purpose, a simple modification shall be made to synchronize the counter and the button. Hopefully this research outcome will be useful for learning digital system in the future.

\section{REFERENCES}

[1] Malvino, A., Elektronika Komputer Digital. Jakarta: Penerbit Erlangga, 1988.

[2] Cavanagh, Digital Computer Arithmatic Design and Implementation. McGraw Hill, 1985.

[3] Holdsworth, Digital Logic Design. Busterworth, 1982.

[4] Tokheim, R., Prinsip-Prinsip Digital. Jakarta: Penerbit Erlangga, 1996.

[5] Budiharto, W., Elektronika Digital dan Mikroprosesor. Yogyakarta: Penerbit ANDI, 2005.

[6] All About Circuits, "Synchronous Counters", All About Circuits.com, 2012. Source: http://www.allaboutcircuits.com/vol 4/chpt 11/3.html

[7] Rompis, L., Designing Synchronous Binary Counter. Jurnal Lasallian Universitas Katolik De la Salle Manado, 2005. 4(2):

[8] Sangadji, E. dan Sopiah, Metodologi Penelitian: Pendekatan Praktis dalam Penelitian. Yogyakarta: Penerbit ANDI, 2010. 